\title{
Measuring thermal conductivity via basic home equipment
}

\author{
Mustafa Erol 1, a. *, Muhammed Emre Kuzucu 1, b \\ ${ }^{1}$ Dokuz Eylül University. 35380, ìzmir, Turkey. \\ a mustafa.erol@deu.edu.tr; ${ }^{b}$ muhammedemre.kuzucu@gmail.com \\ * Corresponding Author.
}

Received: 6 December 2021; Revised: 13 January 2022; Accepted: 20 January 2022

\begin{abstract}
This work reports a trouble-free alternative measuring approach for instructing the puzzling concept of thermal conductivity. In order to accomplish the task, a basic daily used home equipment is employed together with a mathematical modelling approach. Specifically, a simple approach to measure the thermal conductivity coefficient is described and temperature dependence of the thermal conductivity is mathematically modelled. Developed method is interesting in the sense that the experimental equipment is very practical and minimal costing, hence the approach offers physics educators fresh teaching routes and opportunities to clarify the puzzling concept of thermal conductivity and related concepts.

Keywords: Physics education, thermal conductivity, home equipment, mathematical modelling.
\end{abstract}

How to Cite: Erol, M., \& Kuzucu, M. E. (2022). Measuring thermal conductivity via basic home equipment. Momentum: Physics Education Journal, 6(1), 19-28. https://doi.org/10.21067/mpej.v6i1.6306

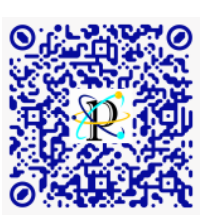

\section{Introduction}

Physics, in general, employs complex concepts to explain the workings of nature and resolves the relationship between those concepts based on mathematical equations. Physics education research (PER), on other hand, conducts research based on teaching of these concepts and relationships between concepts via mathematical equations. PER researchers all over the world strive to make it easier to teach complex and abstract concepts and equations (Retnawati et al., 2018; Zhang et al., 2018).

Thermodynamics is one of the subfields of physics where there are many complications in teaching of physics. When the literature is examined, it is clearly understood that students' misconceptions about the concepts of thermodynamics are intense (Thomaz et al., 1993; Wiser \& Kipman, 1988; Xie, 2012). In this sense, as an example common misconceptions on heat and temperature is determined among physics education students using four-tier diagnostic test (Fenditasari et al., 2020). Recently another work is carried out focusing on the effect of problem type toward students' conceptual understanding level concerning heat and temperature. (Ratnasari et al., 2017). In order to determine misconceptions of thermal concepts, validation of the thermal concept evaluation test for Greek university students' is also carried out (Stylos et al., 2021). The reasons for this can be listed as the abstractness of the concepts, the lack of materials used in thermodynamics teaching, and the fact that the course contents pave the way for misunderstandings (Alwan, 2011; Cotignola et al., 2002; Jasien \& Oberem, 2002; Kulkarni \& Tambade, 2017; Pathare \& Pradhan, 2011; Tatar \& Oktay, 2011). Teaching thermodynamics seems to be one of the problematic areas in physics and therefore it should be discussed in detail (Kemp, 1984; Zacharia \& Constantinou, 2008). Heat conduction, which is one of the complicated thermodynamics issues, is expressed via the thermal conductivity coefficient and it depends on the amount of heat energy transferred, the thickness and surface area of the body that conducts heat transfer, time and temperature difference. Also, considering that the 
thermal conductivity coefficient changes with temperature, the need for alternative materials in teaching these subjects increases because traditional methods would challenge educators to teach such a complex and abstract concept.

Physics progresses and develops based on both different concepts and mathematical expressions, which leads to the conclusion that the mathematical modelling of natural phenomena should be the main theme of physics education (Hestenes, 1987). Scientific equations, in general, are coherent units of structured knowledge, they are often used to form coherent aggregates of factual knowledge by the concerted use of general laws or principles (Hestenes, 1997). Scientists solve natural phenomena using tools such as graphs, charts, diagrams, and eventually arrive at mathematical equations to represent certain physical laws or principles (Brewe, 2008). In general, a model is a substitute object or mental construct, thus a conceptual representation of a real entity. In physics education, models are mostly mathematical equations, that is, physical properties are characterized by measurable variables in models (Hestenes, 1987). In addition, students can be modified by adapting the given mathematical equations to a set of situations to describe and predict physical phenomena or design experiments, thereby learning mathematical modelling skills. However, in an old-style physics classroom, students do not have a clear understanding of what the word 'model' means and therefore do not appreciate its role in teaching physics (Grosslight et al., 1991). The importance of a modelling view of physics for teaching physics is that physics education should give students an insight into the nature of physics as mathematical modelling creativity, modelling accordingly; are receiving increasing attention from physics educators as important components of a fashionable physics education (Gilbert, 2004; Gilbert et al., 2000; Greca \& Moreira, 2002).

Our current study focuses on eliminating the misunderstandings and misconceptions that arise during the teaching of the variables that heat conduction and the thermal conductivity coefficient of an object depend on. For this reason, in our study, an alternative course material including a 3dimensional experimental setup for teaching the thermal conductivity coefficient has been developed. Thanks to the data obtained from the experiment, the mathematical equation that gives the thermal conductivity coefficient is reached by using the mathematical modelling method. Thus, it is tested by a scientifically known method of real experimentation and mathematical modelling. In addition, the materials used in the experiment are advantageous as they can be carried out at a low cost thanks to a few simple materials in addition to the tools found in every home.

\section{Methods}

\section{Research Model}

This work is an effort to develop a basic teaching material on a complicated topic of solid state physics or thermodynamics, namely thermal conductivity. Mathematical modelling approach is offered as the teaching approach and the research model can be stated as a developmental research model.

This study, as stated previously, aims to teach the thermal conductivity coefficient with a mathematical modelling strategy in order to overcome the difficulties experienced by students in analyzing the variables on which the thermal conductivity and thermal conductivity coefficient depend. In line with these objectives, problem situations are specified as follows: (1) How can it be possible to measure thermal conductivity coefficient by using basic home equipment?; (2) How can the thermal conductivity coefficient be mathematically modelled as a function of the temperature?; (3) Does thermal conductivity coefficient depend on the material type?

\section{Experimental Details}

The experimental components used in the approach are mainly the thermometer, caliper, scissors, precision scale, screwdriver, tape, glass container, steel container or coffee pot and insulation material and all components are shown in Figure 1. 


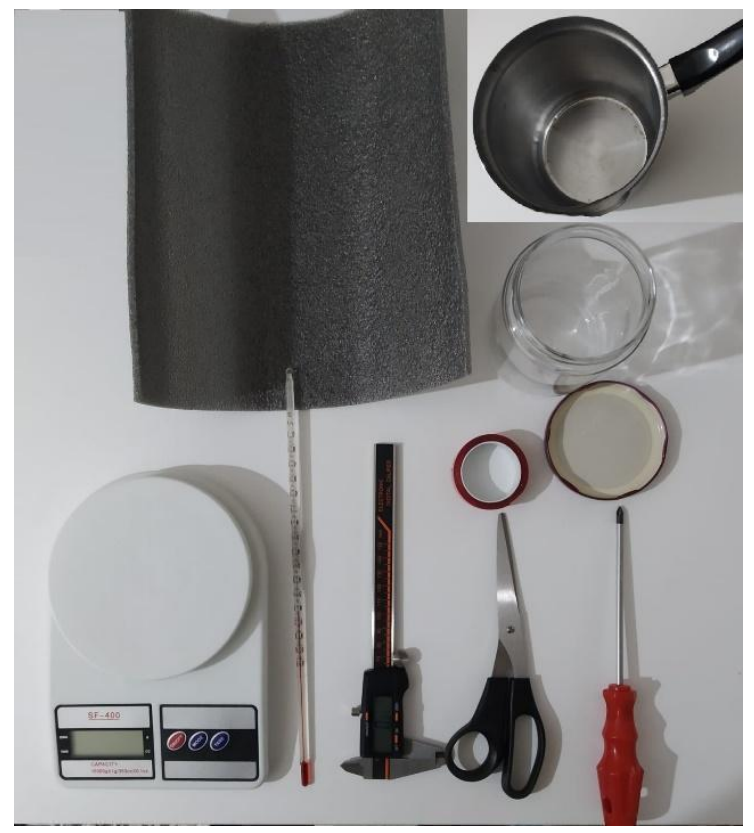

Figure 1. Photography of the components employed in the experiment.

The experimental setup for the two different measurements are shown in Figure 2 . It is important to express, at this stage, that the top of the containers should be well insulated with an appropriate insulating material so that the heat flow from the upper part of the container can be negligible because we only aim to measure the thermal conductivity of the containers, specifically glass or steel. The experimental procedure can be summarized as follows: (1) Boil the water and fill the container to an appropriate level; (2) seal the top of the container; (3) place the thermometer properly; (4) place the container in the fridge; (5) read the temperature of the water at appropriate times and record the exact times and temperatures.
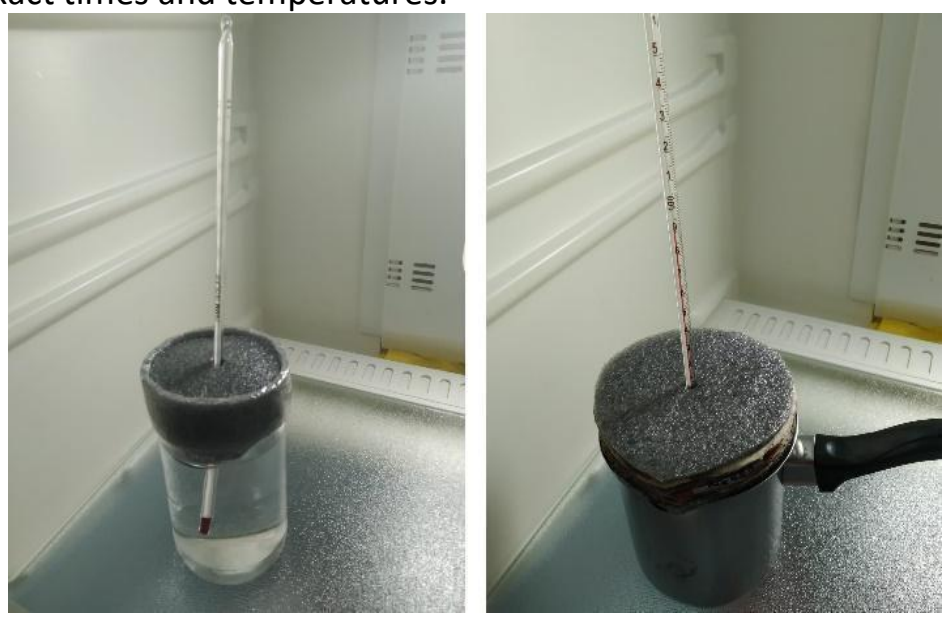

Figure 2. Prepared containers used within the experimental setups.

In order to perform the experiments, initially the thickness of the container, $\Delta x$, and the surface area, $A$, where heat transfer takes place are measured and calculated. Then, the container is filled up with boiling water and the net mass of the water, $m$, and the initial temperature of the water, $T_{w i}$, together with the temperature of the fridge, $T_{f}$, are measured.

\section{Results and Discussion}

\section{Measurement of the Thermal Conductivity Coefficient}

Genuine answer to the 1st problem statement is given by following the procedure detailed below. In order to measure the thermal conductivity coefficient of a certain material, an appropriate 
container made up of that specific material is used by filling up the container with hot water, placing it in a fridge and measuring the temperature change of the hot water, $\Delta T_{w}$ for a certain time period, $\Delta t$. The temperature change of the water within the container is due to the heat energy transfer, $\Delta Q$, between the hot water and the outer surroundings that is the fridge. Measuring the temperature change $\Delta T_{w}=T_{w i}-T_{w f}$ for a certain period of time $\Delta t$, allows to calculate the amount of heat energy transfer, $\Delta Q=m c \Delta T_{w}$, where c obviously denotes the specific heat of the water, $c=4186 \mathrm{~J} / \mathrm{kg}^{\circ} \mathrm{C}$ and $\mathrm{m}$ denotes the mass of the water, $\mathrm{m}=0,500 \mathrm{~kg}$. Specifically in this case initial temperature of the water is set to $T_{w 0}=70.0^{\circ} \mathrm{C}$ and the final temperature of the water is determined as $T_{w f}=60^{\circ} \mathrm{C}$ hence $\Delta T_{w}=70-60=10^{\circ} \mathrm{C}$ consequently $\Delta Q=20930 \mathrm{~J}$. Then transferred thermal power, from the hot water to the environment can also be calculated by means of $\Delta \mathrm{Q} / \Delta \mathrm{t}$ by only measuring the time period $\Delta t$. The temperature gradient between the inner and outer walls of the container can be calculated by, $\frac{\Delta T_{c}}{\Delta x}$, where the temperature difference of the container is given by $\Delta T_{c}=T_{w i}-T_{f}$, where the temperature of the fridge, $T_{f}=13.0^{\circ} \mathrm{C}$ and the thickness of the container is measured as $\Delta x=3.03 \times 10^{-3} \mathrm{~m}$. Finally, the thermal conductivity coefficient can be calculated by using the equation of $K=\frac{1}{A} \frac{\Delta Q}{\Delta t} \frac{\Delta x}{\Delta T_{c}}$ where the area of the container is measured as $A=0.0489 \mathrm{~m}^{2}$, and the temperature gradient is determined as $\frac{\Delta T_{c}}{\Delta x}=15511.6 \frac{{ }^{\circ} \mathrm{C}}{\mathrm{m}}$. Table 1 gives the results of 10 sequential measurements and the calculation results for the thermal conductivity coefficient.

Table 1. Thermal conductivity coefficient measurements for the glass.

\begin{tabular}{cccc}
\hline No. & $\Delta \boldsymbol{t}(\mathrm{s})$ & $\frac{\Delta \boldsymbol{Q}}{\Delta \boldsymbol{t}}(\boldsymbol{J} / \mathbf{s})$ & $\boldsymbol{K}=\frac{\mathbf{1}}{\boldsymbol{A}} \frac{\boldsymbol{\Delta Q}}{\Delta \boldsymbol{t}} \frac{\Delta \boldsymbol{x}}{\Delta \boldsymbol{T}_{\boldsymbol{c}}}\left(\mathbf{1 0}^{-\mathbf{2}} \boldsymbol{W} / \mathbf{m} \boldsymbol{K}\right)$ \\
\hline 1. & 761 & 27.50 & 3.626 \\
2. & 765 & 27.36 & 3.607 \\
3. & 768 & 27.25 & 3.593 \\
4. & 762 & 27.47 & 3.622 \\
5. & 768 & 27.25 & 3.593 \\
6. & 770 & 27.18 & 3.583 \\
7. & 769 & 27.22 & 3.589 \\
8. & 768 & 27.25 & 3.593 \\
9. & 770 & 27.18 & 3.583 \\
10. & 771 & 27.15 & 3.579 \\
\hline
\end{tabular}

The procedure offered can usefully be employed to measure the thermal conductivity coefficient in cases where the change in the thermal conductivity coefficient with temperature is ignored. In our experiment, the actual average of the thermal conductivity coefficient is found to be $\mathrm{K}=3.59710-2 \mathrm{~W} / \mathrm{m} \mathrm{K}$ for glass which is reasonably small compared to the accepted value of $0.8 \mathrm{~W} / \mathrm{m}$ $\mathrm{K}$ at room temperatures. The difference is attributed to the experimental conditions, specifically due to the refrigerator door being opened and closed several times to check the thermometer and it is obvious that the inside of the refrigerator would not remain at a constant temperature at that conditions. However, the main aim of the work is to offer how to measure the coefficient of thermal conductivity for only teaching purposes. A number of efforts have recently been reported supporting our work. A hot-wire method based thermal conductivity measurement is recently achieved in harmony with our results (Alvarado et al., 2012). In order to measure the thermal conductivity, a digital instrument designed and used for teaching activities (Zheng et al., 2019).

\section{Mathematical Modelling of the Temperature Dependence of the Thermal Conductivity}

The processes described above can easily be employed to determine the temperature dependence of the thermal conductivity coefficient. To do so, the container full of hot water is placed in the fridge and as the hot water cools down the temperature of the water is measured for 
every $\Delta t=3$ minutes. Specific parameters for the glass container are measured and given as follows, the mass of the water, $\mathrm{m}=0.500 \mathrm{~kg}$, the inner temperature of the fridge, $T_{f}=10.0^{\circ} \mathrm{C}$, the thickness of the wall of the container, $\Delta x=3.03 \times 10^{-3} \mathrm{~m}$, the surface area of the container, $A=0.0489 \mathrm{~m}^{2}$, specific heat of the water, $c=4186 \mathrm{~J} / \mathrm{kg}^{\circ} \mathrm{C}$. The temperature change of the water for 3 minutes is basically calculated from, $\Delta T_{w}=T_{w i}-T_{w f}$, where $T_{w i}$ denotes the initial temperature of the water and $T_{w f}$ denotes the final temperature. Then the heat energy transfer for any temperature interval within 3 minutes is given by, $\Delta Q=m c \Delta T_{w}$. Transferred heat power is given by, $\frac{\Delta Q}{\Delta t}$, and similarly the temperature gradient is given by, $\frac{\Delta T_{c}}{\Delta x}$, where the temperature difference for the container wall is given by $\Delta T_{c}=T_{w 0}-T_{f}$. Consequently, the thermal conductivity coefficient is then given by, $K=\frac{1}{A} \frac{\Delta Q}{\Delta t} \frac{\Delta x}{\Delta T_{c}}$. The thermal conductivity coefficient is calculated for the average temperature which is given by $T=\frac{T_{w i}+T_{w f}}{2}$. The actual measurements and calculations are given in Table 2 .

Table 2. Determination of the temperature dependence of the thermal conductivity coefficient for the material of glass.

\begin{tabular}{cccccc}
\hline $\mathrm{T}\left({ }^{\circ} \mathrm{C}\right)$ & $\Delta \boldsymbol{T}_{\boldsymbol{w}}=\boldsymbol{T}_{\boldsymbol{w i}}-\boldsymbol{T}_{\boldsymbol{w} f}\left({ }^{\circ} \mathrm{C}\right)$ & $\Delta \boldsymbol{Q}=\boldsymbol{m} \boldsymbol{c} \Delta \boldsymbol{T}_{\boldsymbol{w}}(\boldsymbol{J})$ & $\frac{\Delta \boldsymbol{Q}}{\Delta \boldsymbol{t}}(\boldsymbol{J} / \boldsymbol{s})$ & $\frac{\Delta \boldsymbol{T}_{\boldsymbol{c}}}{\Delta \boldsymbol{x}}\left({ }^{\circ} \mathrm{C} / \boldsymbol{m}\right)$ & $\boldsymbol{K}=\frac{\mathbf{1}}{\boldsymbol{A}} \frac{\Delta \boldsymbol{Q}}{\Delta \boldsymbol{t}} \frac{\Delta \boldsymbol{\Delta}}{\Delta \boldsymbol{T}_{\boldsymbol{c}}}(\boldsymbol{W} / \boldsymbol{m} \boldsymbol{K})$ \\
\hline 88 & 2 & 4186 & 23.26 & 660.1 & 0.72 \\
86 & 4 & 8372 & 23.26 & 1320.1 & 0.36 \\
84 & 6 & 12558 & 23.26 & 1980.2 & 0.24 \\
81 & 9 & 18837 & 26.16 & 2970.3 & 0.18 \\
79 & 11 & 23023 & 25.58 & 3630.4 & 0.14 \\
77 & 13 & 27209 & 25.19 & 4290.4 & 0.12 \\
75 & 15 & 31395 & 24.92 & 4950.5 & 0.10 \\
73 & 17 & 35581 & 24.71 & 5610.6 & 0.09 \\
72 & 19 & 39767 & 24.55 & 6270.6 & 0.08 \\
70 & 20 & 41860 & 23.26 & 6600.7 & 0.07 \\
68 & 22 & 46046 & 23.26 & 7260.7 & 0.07 \\
66 & 24 & 50232 & 23.26 & 7920.8 & 0.06 \\
65 & 25 & 52325 & 22.36 & 8250.8 & 0.06 \\
63 & 27 & 56511 & 22.43 & 8910.9 & 0.05 \\
61 & 29 & 60697 & 22.48 & 9571.0 & 0.05 \\
60 & 30 & 62790 & 21.80 & 9901.0 & 0.04 \\
59 & 31 & 64883 & 21.20 & 10231.0 & 0.04 \\
57 & 33 & 69069 & 21.32 & 10891.1 & 0.04 \\
56 & 34 & 71162 & 20.81 & 11221.1 & 0.04 \\
54 & 36 & 75348 & 20.93 & 11881.2 & 0.04 \\
\hline
\end{tabular}

In order to mathematically model the temperature dependence of the thermal conductivity coefficient for the Glass, the data given above is used and thermal conductivity coefficient per unit area is plotted as a function of the temperature. The plot for the glass is given in Figure 3 . The curve fitting of the graph gives the mathematical relation as. $\mathrm{K}=0.0005 \mathrm{e} 0,0735 \mathrm{~T}$.

The same processes were repeated for the steel container and the results are presented in Table 3. The specific parameters for this experiment are measured or calculated and given as follows; the mass of the water, $\mathrm{m}=0.600 \mathrm{~kg}$, the temperature of the fridge, $T_{f}=10.0^{\circ} \mathrm{C}$, the thickness of the container, $\Delta x=4.9 \times 10^{-4} \mathrm{~m}$, the surface area of the container, $A=0.0512 \mathrm{~m}^{2}$, specific heat of the water, $c=4186 \mathrm{~J} / \mathrm{kg}^{\circ} \mathrm{C}$.

The plot for the steel is given in Figure 4. The curve fitting of the graph gives the mathematical relation as $\mathrm{K}=0.0048 \mathrm{e} 0,082 \mathrm{~T}$. 


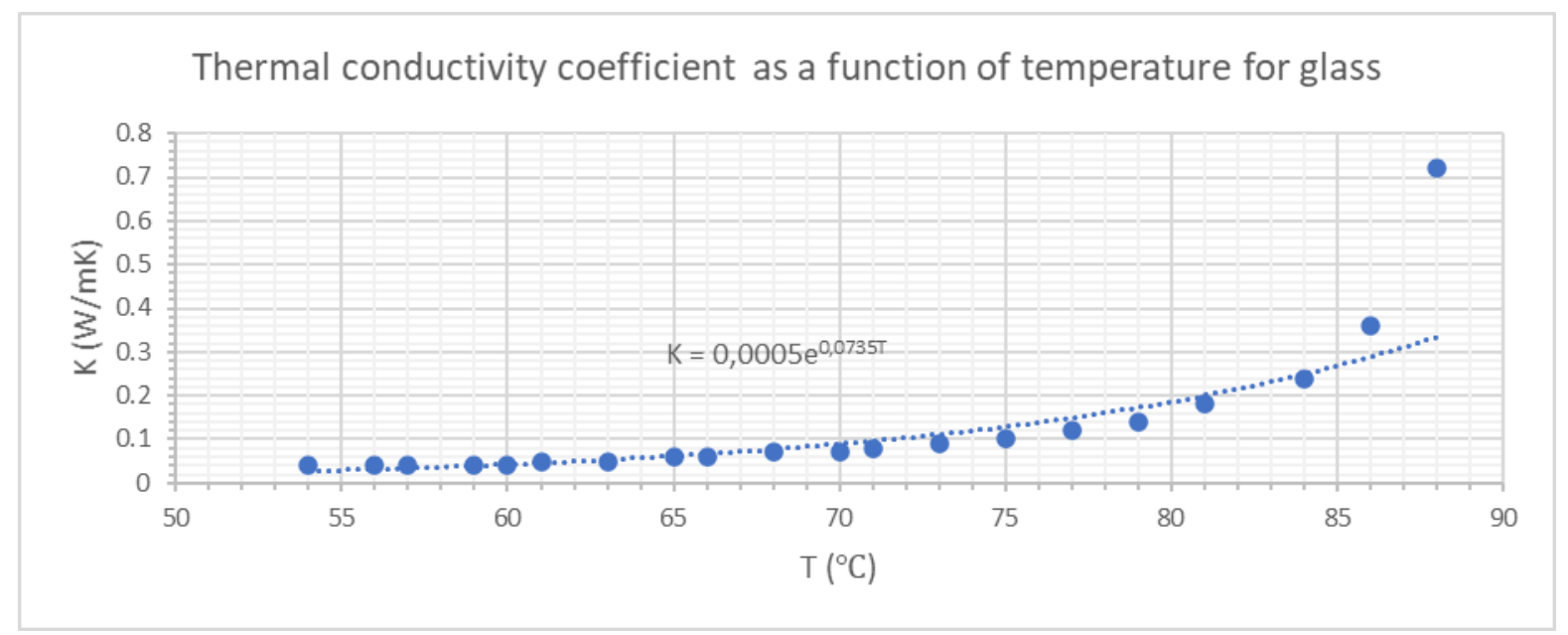

Figure 3. Thermal conductivity coefficient plotted as a function of temperature for the material of glass.

Table 3. Determination of the temperature dependence of the thermal conductivity coefficient for the material of steel.

\begin{tabular}{cccccc}
\hline $\mathrm{T}\left({ }^{\circ} \mathrm{C}\right)$ & $\Delta \boldsymbol{T}_{\boldsymbol{w}}=\boldsymbol{T}_{\boldsymbol{w i}}-\boldsymbol{T}_{\boldsymbol{w} f}\left({ }^{\circ} \mathrm{C}\right)$ & $\Delta \boldsymbol{Q}=\boldsymbol{m} \boldsymbol{c} \Delta \boldsymbol{T}_{\boldsymbol{w}}(\boldsymbol{J})$ & $\frac{\Delta \boldsymbol{Q}}{\Delta \boldsymbol{t}}(\boldsymbol{J} / \boldsymbol{s})$ & $\frac{\Delta \boldsymbol{T}_{\boldsymbol{c}}}{\Delta \boldsymbol{x}}\left({ }^{\circ} \mathrm{C} / \boldsymbol{m}\right)$ & $\boldsymbol{K}=\frac{\mathbf{1}}{\boldsymbol{A}} \frac{\Delta \boldsymbol{Q}}{\Delta \boldsymbol{t}} \frac{\Delta \boldsymbol{x}}{\Delta \boldsymbol{T}_{\boldsymbol{c}}}(\boldsymbol{W} / \boldsymbol{m} \boldsymbol{K})$ \\
\hline 88 & 2 & 5023 & 27.91 & 4081.6 & 13.96 \\
86 & 4 & 10046 & 27.91 & 8163.3 & 6.98 \\
84 & 6 & 15070 & 27.91 & 12244.9 & 4.65 \\
82 & 8 & 20093 & 27.91 & 16326.5 & 3.49 \\
80 & 10 & 25116 & 27.91 & 20408.2 & 2.79 \\
78 & 12 & 30139 & 27.91 & 24489.8 & 2.33 \\
76 & 14 & 35162 & 27.91 & 28571.4 & 1.99 \\
75 & 15 & 37674 & 26.16 & 30612.2 & 1.74 \\
73 & 17 & 42697 & 26.36 & 34693.9 & 1.55 \\
71 & 19 & 47720 & 26.51 & 38775.5 & 1.40 \\
70 & 20 & 50232 & 25.37 & 40816.3 & 1.27 \\
68 & 22 & 55255 & 25.58 & 44898.0 & 1.16 \\
67 & 23 & 57767 & 24.69 & 46938.8 & 1.07 \\
65 & 25 & 62790 & 24.92 & 51020.4 & 1.00 \\
64 & 26 & 65302 & 24.19 & 53061.2 & 0.93 \\
62 & 28 & 70325 & 24.42 & 57142.9 & 0.87 \\
61 & 29 & 72836 & 23.80 & 59183.8 & 0.82 \\
60 & 30 & 75348 & 23.26 & 61224.5 & 0.78 \\
59 & 31 & 77860 & 22.77 & 63265.3 & 0.73 \\
58 & 32 & 80371 & 22.33 & 65306.1 & 0.70 \\
\hline
\end{tabular}

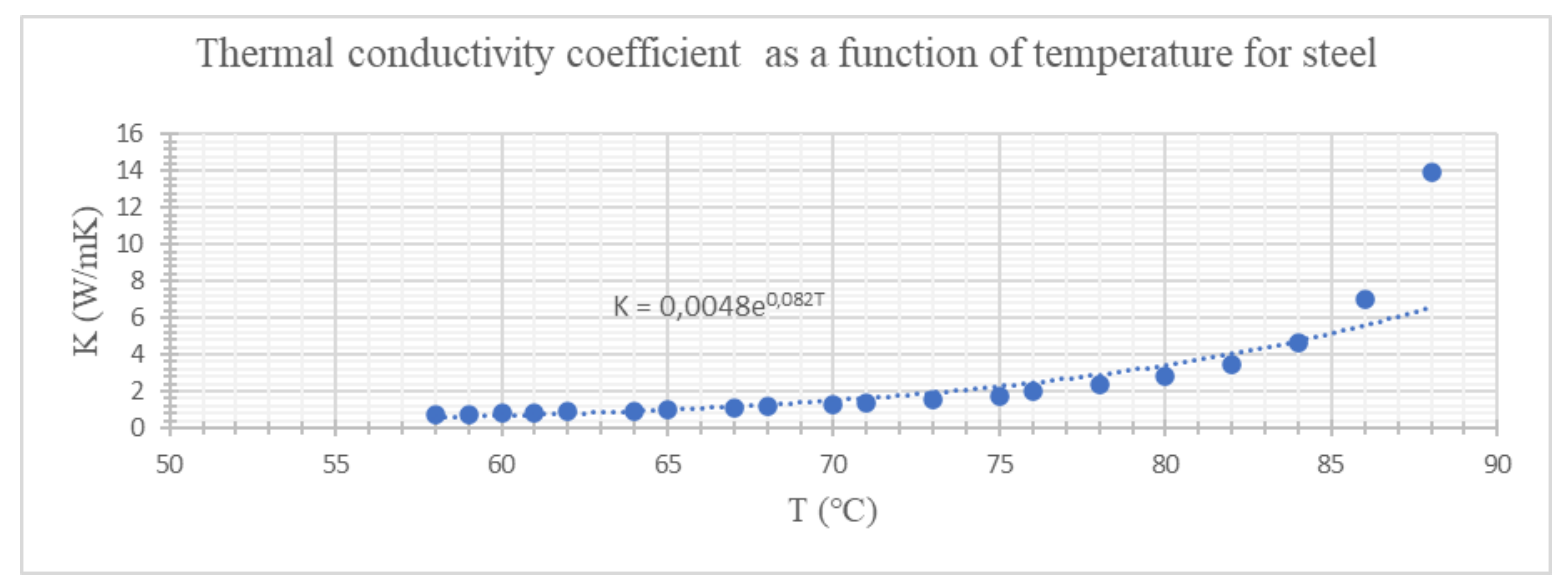

Figure 4. Thermal conductivity per unit area plotted as a function of temperature for the material of steel. 
In the Figure 4 given for both glass and steel, the variation of the thermal conductivity coefficient with temperature is non-linear. The thermal conductivity coefficient increases with temperature exponentially, specifically $\mathrm{K}=0.0005 \mathrm{e} 0,0735 \mathrm{~T}$ for glass and $\mathrm{K}=0.0048 \mathrm{e} 0,082 \mathrm{~T}$ for steel. These mathematical relations can surely be attributed to complicated and different scattering mechanisms determining the thermal conductivity and varying with temperature.

\section{Thermal Conductivity Coefficients of Different Materials}

Thermal conductivity coefficient of the materials, as stated previously, depends strongly on the scattering mechanism which is a characteristic of the related material. In order to demonstrate this scientific reality and thus to solve the third problem case, we performed this experiment with both glass and steel. When the thermal conductivity coefficients for the unit surface area given in Table 2 and table 3 are compared for glass and steel, it is clearly seen that the values calculated for steel are higher at different temperature values. This comparison is made in Table 4 . This result shows us that steel conducts heat better and that the coefficient of thermal conductivity depends on the type of material.

Table 4. Thermal conductivity coefficient for different temperatures according to material type

\begin{tabular}{ccc}
\hline $\boldsymbol{T}\left({ }^{\circ} \mathrm{C}\right)$ & \multicolumn{2}{c}{$\mathrm{K}(\boldsymbol{W} / \boldsymbol{m} \boldsymbol{K})$} \\
\cline { 2 - 3 } & Glass & Steel \\
\hline 88 & 0.72 & 13.96 \\
84 & 0.24 & 4.65 \\
75 & 0.10 & 1.74 \\
70 & 0.07 & 1.27 \\
65 & 0.06 & 1.00 \\
60 & 0.04 & 0.78 \\
\hline
\end{tabular}

\section{Conclusion}

The present work is an effort to offer an alternative teaching material for the puzzling concept of thermal conductivity. Specifically following problem statements have been tackled; (1) How can it be possible to measure thermal conductivity coefficient by using basic home equipment? (2) How can the thermal conductivity coefficient be mathematically modelled as a function of the temperature? (3) Does thermal conductivity coefficient depend on the material type?

The first problem statement is answered by developing a basic home equipment mainly consisting of a container, a thermometer, a fridge and a timer. Using this approach, the average thermal conductivity coefficient for glass is measured to be $\mathrm{K}=0.03597 \mathrm{~W} / \mathrm{m} \mathrm{K}$. Second problem statement is tackled by measuring and plotting the temperature dependence of the thermal conductivity for both glass and steel between the temperatures of $88 \mathrm{~K}$ and $58 \mathrm{~K}$. The mathematical relations are found to be $K=0.0005 e 0,0735 \mathrm{~T}$ for glass and $\mathrm{K}=0.0048 \mathrm{e} 0,082 \mathrm{~T}$ for steel. Finally, the material dependence of the thermal conductivity is resolved for teaching purposes by comparing the two specific measurements for both glass and steel.

The method suggested is motivating in the sense that the 3D basic home equipment is very practical and minimal costing, hence it compromises physics educators new teaching paths and opportunities to clarify the confusing concept of thermal conductivity.

\section{References}

Alvarado, S., Marín, E., Juárez, A. G., Calderón, A., \& Ivanov, R. (2012). A hot-wire method based thermal conductivity measurement apparatus for teaching purposes. European Journal of Physics, 33(4), 897-906. https://doi.org/10.1088/0143-0807/33/4/897

Alwan, A. A. (2011). Misconception of heat and temperature Among physics students. Procedia Social and Behavioral Sciences, 12, 600-614. https://doi.org/10.1016/j.sbspro.2011.02.074

Brewe, E. (2008). Modeling theory applied: Modeling Instruction in introductory physics. American 
Journal of Physics, 76(12), 1155-1160. https://doi.org/10.1119/1.2983148

Cotignola, M. I., Bordogna, C., Punte, G., \& Cappannini, O. M. (2002). Difficulties in learning thermodynamic concepts are they linked to the historical development of this field? Science \& Education, 11(3), 279-291. https://doi.org/10.1023/A:1015205123254

Fenditasari, K., Jumadi, Istiyono, E., \& Hendra. (2020). Identification of misconceptions on heat and temperature among physics education students using four-tier diagnostic test. Journal of Physics: Conference Series, 1470(1), 012055. https://doi.org/10.1088/1742$6596 / 1470 / 1 / 012055$

Gilbert, J. K. (2004). Models and modelling: Routes to more authentic science education. International Journal of Science and Mathematics Education, 2(2), 115-130. https://doi.org/10.1007/s10763-004-3186-4

Gilbert, J. K., Boulter, C. J., \& Elmer, R. (2000). Positioning models in science education and in design and technology education. In Developing Models in Science Education (pp. 3-17). Springer Netherlands. https://doi.org/10.1007/978-94-010-0876-1_1

Greca, I. M., \& Moreira, M. A. (2002). Mental, physical, and mathematical models in the teaching and learning of physics. Science Education, 86(1), 106-121. https://doi.org/10.1002/sce.10013

Grosslight, L., Unger, C., Jay, E., \& Smith, C. L. (1991). Understanding models and their use in science: Conceptions of middle and high school students and experts. Journal of Research in Science Teaching, 28(9), 799-822. https://doi.org/10.1002/tea.3660280907

Hestenes, D. (1987). Toward a modeling theory of physics instruction. American Journal of Physics, 55(5), 440-454. https://doi.org/10.1119/1.15129

Hestenes, D. (1997). Modeling methodology for physics teachers. AIP Conference Proceedings, 399, 935-958. https://doi.org/10.1063/1.53196

Jasien, P. G., \& Oberem, G. E. (2002). Understanding of elementary concepts in heat and temperature among college students and K-12 teachers. Journal of Chemical Education, 79(7), 889. https://doi.org/10.1021/ed079p889

Kemp, H. R. (1984). The concept of energy without heat or work. Physics Education, 19(5), 003. https://doi.org/10.1088/0031-9120/19/5/003

Kulkarni, V. D., \& Tambade, P. S. (2017). Assessing the conceptual understanding about heat and thermodynamics at undergraduate level. European Journal Of Physics Education, 4(2), 9-16. http://www.eu-journal.org/index.php/EJPE/article/view/85

Pathare, S., \& Pradhan, H. C. (2011). Students' alternative conceptions in pressure, heat and temperature. Physics Education, 21(3-4), 213-218. https://www.hbcse.tifr.res.in/episteme/episteme-1/allabs/shirish_abs.pdf

Ratnasari, D., Sukarmin, S., \& Suparmi, S. (2017). Effect of problem type toward students' conceptual understanding level on heat and temperature. Journal of Physics: Conference Series, 909(1), 012054. https://doi.org/10.1088/1742-6596/909/1/012054

Retnawati, H., Arlinwibowo, J., Wulandari, N., \& Pradani, R. (2018). Teachers' difficulties and strategies in physics teaching and learning that applying mathematics. Journal of Baltic Science Education, 17(1), 120-135. http://www.scientiasocialis.It/jbse/?q=node/643

Stylos, G., Sargioti, A., Mavridis, D., \& Kotsis, K. T. (2021). Validation of the thermal concept evaluation test for Greek university students' misconceptions of thermal concepts. International Journal of Science Education, 43(2), 247-273. https://doi.org/10.1080/09500693.2020.1865587

Tatar, E., \& Oktay, M. (2011). The effectiveness of problem-based learning on teaching the first law of thermodynamics. Research in Science \& Technological Education, 29(3), 315-332. https://doi.org/10.1080/02635143.2011.599318

Thomaz, M. F., Malaquias, I. M., Valente, M. C., \& Antunes, M. J. (1993). Case study of a sixth grade 
class: Attitudes and conceptions of the marine environment. Third International Seminar on Misconceptions and Educational Strategies in Science and Mathematics.

Wiser, M., \& Kipman, D. (1988). The differentiation of heat and temperature: an evaluation of the effect of microcomputer models on students' misconceptions. ETC-TR-88-20

Xie, C. (2012). Interactive heat transfer simulations for everyone. The Physics Teacher, 50(4), 237240. https://doi.org/10.1119/1.3694080

Zacharia, Z. C., \& Constantinou, C. P. (2008). Comparing the influence of physical and virtual manipulatives in the context of the Physics by Inquiry curriculum: The case of undergraduate students' conceptual understanding of heat and temperature. American Journal of Physics, 76(4), 425-430. https://doi.org/10.1119/1.2885059

Zhang, C., Wang, H., Liu, Y., \& Jiang, J. (2018). Investigation and the improvement strategy of the inquiry physics experiment teaching in senior high school. American Journal of Physics and Applications, 6(5), 104. https://doi.org/10.11648/j.ajpa.20180605.11

Zheng, W., Feng, L., Liu, B., Fu, P., Yin, H., \& Qiao, J. (2019). Instrument design for digital thermal conductivity measurement. 2019 IEEE International Instrumentation and Measurement Technology Conference (I2MTC), 1-5. https://doi.org/10.1109/I2MTC.2019.8827026 